Revista de Investigación Educativa 27

julio-diciembre, 2018 | ISSN 1870-5308 | Xalapa, Veracruz

Instituto de Investigaciones en Educación | Universidad Veracruzana

\title{
Diálogo de saberes en la vinculación comunitaria: Aportes desde las experiencias y comprensiones de los estudiantes de la Universidad Intercultural de Chiapas
}

\section{Dialogue of knowledge in the community bond: Contributions from the experiences and understandings of the students of the Intercultural University of Chiapas}

\author{
Stefano Sartorello \\ Joaquín Peña Piña
}

Recibido: 27 de febrero de 2018

Aceptado: 25 de junio de 2018

Este escrito vierte sobre el diálogo de saberes en los procesos de vinculación comunitaria realizados por estudiantes de la carrera de Desarrollo Sustentable de la Universidad Intercultural de Chiapas. Este tema se analiza desde el enfoque de la interculturalidad crítica y los planteamientos que surgen de la teoría decolonial y la epistemología del Sur. A partir de las experiencias y comprensiones de los estudiantes sobre sus prácticas de vinculación, se definen tres dimensiones analíticas — axiológica, epistemológica y de la acción finalizada-, interconectadas entre sí en una espiral del diálogo de saberes. Con base en estas dimensiones se presentan los análisis de los estudiantes sobre las prácticas de vinculación comunitaria llevadas a cabo a lo largo de su carrera, y se definen aportes que retroalimentan el modelo educativo de las universidades interculturales y los procesos de vinculación que se llevan a cabo en la Universidad Intercultural de Chiapas.

Palabras clave: Universidades interculturales; vinculación comunitaria; diálogo de saberes.

\footnotetext{
a Doctor en educación. Profesor-Investigador, Instituto de Investigaciones para el Desarrollo de la Educación, Universidad Iberoamericana de la Ciudad de México.凶 stepol 2000@yahoo.com

${ }^{\text {b }}$ Doctor en Desarrollo Sustentable. Profesor-Investigador, Universidad Intercultural de Chiapas, México.凶 joaquinpp@unich.edu.mx
} 
This article pours about the dialogue of knowledge in the processes of community bonding carried out by students of the career of Sustainable Development of the Intercultural University of Chiapas (UNICH). This topic is analyzed from the approach of critical interculturality and the approaches that arise from decolonial theory and epistemology of the South. From the students' experiences and understandings about their linking practices, three analytical dimensions are defined - axiological, epistemological and finalized action- interconnected in a spiral of the dialogue of knowledge. Based on these dimensions, students 'analyzes of community engagement practices carried out throughout their careers are presented, and contributions are defined that provide feedback to the intercultural universities' educational model and the bonding processes that are carried out at the UNICH.

Keywords: Intercultural universities; community bond; knowledge dialogue.

\title{
Diálogo de saberes en la vinculación comunitaria: Aportes desde las experiencias y comprensiones de los estudiantes de la Universidad Intercultural de Chiapas
}

\author{
Dialogue of knowledge in the community bond: \\ Contributions from the experiences and understandings of \\ the students of the Intercultural University of Chiapas
}

\section{Introducción}

$\mathrm{E}^{\mathrm{n}}$ n este artículo se analiza el tema del diálogo de saberes en los procesos de vinculaCión comunitaria (DDs en la vC, de aquí en adelante) a partir de las reflexiones realizadas por 41 estudiantes (19 hombres y 22 mujeres) de la octava (2012-2016) y novena generación (2013-2017) de la licenciatura en Desarrollo Sustentable (DS) de la Universidad Intercultural de Chiapas (UNICH). Estos jóvenes universitarios, que 
han sido alumnos de los autores del presente escrito a lo largo de toda su carrera, participaron en el proyecto de investigación "Entre lo propio y lo ajeno: Diálogo de saberes y construcción intercultural del conocimiento en instituciones y programas educativos con enfoque intercultural de México", ${ }^{1}$ desarrollado entre enero 2016 y diciembre 2017 por Stefano Sartorello desde el Instituto de Investigaciones para el Desarrollo de la Educación (INIDE) de la Universidad Iberoamericana de la Ciudad de México, en colaboración con, entre otros académicos, Joaquín Peña de la UNICH. A través de un proceso meta-cognitivo, desarrollado en el marco del Seminario de Evaluación del Desarrollo Sustentable (octavo semestre de la carrera) y finalizado a que las y los estudiantes reflexionaran sobre los alcances y las implicaciones de las prácticas de vinculación comunitaria realizadas a lo largo de su licenciatura, nos propusimos comprender cuáles han sido las principales dimensiones que, a su consideración, han orientado el diálogo entre los sistemas de conocimiento de los habitantes de las comunidades rurales indígenas en las que realizaron sus prácticas de vinculación y el mal llamado conocimiento académico "universal", del cual son portadores en cuanto estudiantes universitarios.

Es menester señalar que, aunque las universidades interculturales como la UNICH asumen el diálogo de saberes como eje fundamental de las actividades de docencia, investigación y vinculación comunitaria (Casillas \& Santini, 2006), hacen falta "investigaciones empíricas que documenten cómo se da en la práctica universitaria este diálogo entre lo académico y lo comunitario, entre áulico-conceptual y vivencial" (Mateos \& Dietz, 2013, p. 367). En nuestra consideración, la investigación del DDs en la vC, realizada desde las perspectivas y comprensiones de los propios estudiantes, es de

1. El propósito general de este proyecto de investigación, que también se realizó en el Instituto Superior Intercultural Ayuuk (ISIA) del Sistema Universitario Jesuita (sUJ), fue generar una propuesta teórico-metodológica para orientar los procesos interculturales de construcción del conocimiento en instituciones y programas educativos de nivel superior con enfoque intercultural que operan en México. Cabe señalar que en este escrito solamente se abarcará el caso de la UNICH, dejando para futuras contribuciones el caso del ISIA y el análisis comparativo entre ambas experiencias que está todavía en proceso. Finalmente, no es de menor importancia mencionar que los 41 estudiantes de la UNICH de la octava y novena generación fueron informados desde un principio del proyecto y de sus objetivos, y aceptaron participar en ello dedicando algunas horas extra de sus clases regulares.

2. Se utilizan intencionalmente las comillas para referirse al mal llamado conocimiento universal, término con el que se ha atribuido el carácter de universal a un conjunto de conocimientos, prácticas y saberes propios de las sociedades europeas y occidentales. Con ello no se pretende afirmar que los conocimientos indígenas no deberían formar parte de los conocimientos universales, sino destacar una asimetría real que es producto de lo que Quijano (2000) ha denominado con el concepto de "colonialidad del saber". 
suma relevancia para el campo de la educación intercultural, ya que es justamente en el cruce, encuentro o conflicto entre lo propio y lo ajeno ${ }^{3}$ (Bonfil, 1988) donde se ubica el núcleo fundamental de toda propuesta educativa intercultural. Estamos convencidos de que uno de los momentos más importantes de cualquier proceso educativo intercultural ocurre justamente cuando se relacionan entre sí conocimientos recíprocamente otros que responden a racionalidades y lógicas epistémicas diferentes, con el fin de articularlos o bien contrastarlos ${ }^{4}$ entre sí para construir nuevos conocimientos interculturales. Como mostraremos en las conclusiones del presente escrito, las experiencias y comprensiones de los estudiantes de la UNICH constituyen aportaciones relevantes que pueden retroalimentar el Modelo educativo de las universidades interculturales (Casillas \& Santini, 2006), fortalecer los procesos de vinculación de la carrera de Desarrollo Sustentable de la UNICH, promoviendo procesos de DDS más acordes con los principios que plantean Argueta y Pérez (2011), Gasché (2008b) y Leff (2004), entre otros autores que se revisan en los referentes teóricos de este escrito.

No es de menor importancia señalar que el corpus en el que se fundamentan nuestros análisis se construyó a partir de la realización de dos talleres presenciales ${ }^{5}$ caracterizados por la participación activa de los estudiantes. A partir de la recuperación de sus saberes previos, se identificaron tres dimensiones analíticas - axiológica, epistemológica y de la acción finalizada-, interconectadas en la que denominamos espiral del diálogo de saberes, y sobre las cuales profundizaremos más adelante. Fueron estas tres dimensiones las que guiaron las reflexiones escritas de los estudiantes sobre las prácticas de vinculación realizadas a lo largo de su carrera. Será justamente a partir de los 41 textos escritos por estos jóvenes como, en la segunda parte de este artículo, analizaremos los alcances y las implicaciones del DDs en la vC, sustentando nuestras interpretaciones en sus experiencias y comprensiones.

3. Para Bonfil (1988):

Son elementos propios, los que la unidad social considerada ha recibido como patrimonio cultural heredado de generaciones anteriores y los que produce, reproduce, mantiene o transmite [...]. Inversamente, son elementos culturales ajenos aquellos que forman parte de la cultura que vive el grupo, pero que éste no ha producido ni reproducido. En situaciones de contacto interétnico, particularmente cuando las relaciones entre los grupos son asimétricas, de dominación/sujeción, la cultura [...] incluirá tanto elementos propios como ajenos. (p. 7)

4. Sobre el tema de la articulación-contrastación entre conocimientos indígenas rurales y conocimientos académicos, véase Sartorello (2014).

5. En el caso de la octava generación, este taller se realizó el jueves 3 de febrero de 2016, mientras que, en el caso de la novena generación, se llevó a cabo el miércoles 3 de mayo de 2017. En ambos casos, los estudiantes aceptaron dedicar tiempo extra a sus clases para participar en el taller. 
Ahora bien, antes de analizar este corpus, es necesario abrir un paréntesis para explicar cómo se concibe y qué papel se le atribuye a la vinculación comunitaria y al diálogo de saberes en el Modelo educativo de las universidades interculturales en México y en la UNICH.

En la Universidad Intercultural, la vinculación con la comunidad se constituye a partir de considerar que existen formas de pensamiento que, por una parte, están distribuidas entre los diferentes actores sociales que conforman la comunidad, así como en los distintos espacios comunitarios. La estrategia de esta función universitaria se establece al reconocer y reconstruir dichos conocimientos y espacios en oportunidades de proyectos de desarrollo social y productivo para el desarrollo local y regional. (Casillas \& Santini, 2006, p. 153)

Derivado de lo anterior, los lineamientos curriculares de la Coordinación General de Educación Intercultural Bilingüe (CGEIB) plantean que la vinculación comunitaria es una función sustantiva de la universidad que articula la docencia con la investigación, generando "acciones [...] para la atención de problemáticas y necesidades específicas [aportando] soluciones [que] coadyuven al desarrollo social, cultural y productivo de las comunidades" (Casillas \& Santini, 2006, pp. 153-154).

A partir de estos lineamientos generales, en un escrito previo elaborado por uno de los coautores del presente, se muestra cómo, en la licenciatura en Desarrollo Sustentable de la UNICH, la vinculación comunitaria y el diálogo de saberes se han convertido en un eje formativo que atraviesa toda la carrera y que articula de manera horizontal y vertical el mapa curricular "a través de un proceso formativo de complejidad creciente, que contribuye a la formación integral del estudiante mediante la interacción de los saberes disciplinarios y comunitarios" (Peña, 2017, p. 269).

Peña (2017) explica que el eje de vinculación comunitaria tiene el objetivo de articular los saberes propios del estudiante, los saberes académicos del aula y los saberes locales de las comunidades de vinculación, para impulsar "un proceso de aprendizaje creciente y continuo a lo largo de la formación profesional, que permite avanzar en la comprensión y práctica de la sustentabilidad y la interculturalidad" (p. 265).

Este eje se conforma por ocho asignaturas ${ }^{6}$ que, del primer hasta el octavo semes-

6. Del primer al octavo semestre, en el eje de vinculación comunitaria los estudiantes cursan las siguientes materias: Vinculación comunitaria e interculturalidad, Procesos de vinculación comunitaria, Introducción al diálogo de saberes, Trabajo comunitario participativo, Estrategias locales de planeación, Gestión y mediación para la sustentabilidad, Investigación acción comunitaria, Evaluación del desarrollo sustentable (Peña, 2017, p. 270). 
tre, proveen los insumos teórico-metodológicos ${ }^{7}$ que orientan el trabajo de vinculación que los estudiantes realizan desde el inicio de la carrera en comunidades prevalentemente indígenas y rurales del estado de Chiapas, con el fin de "entender cómo los actores locales conciben su desarrollo y cultura local, para proponer las alternativas de solución más adecuadas a su contexto" (Peña, 2017, p. 271).

En las prácticas de vinculación comunitaria que, reunidos en equipos de 4-5 integrantes, realizan a lo largo de toda la carrera, estos jóvenes aplican los conocimientos aprendidos en sus clases universitarias para realizar diagnósticos sociales, económicos, territoriales y productivos de la comunidad y, a partir del quinto semestre, implementan talleres participativos sobre temas de interés para los pobladores de las comunidades; entre ellos, sólo por citar algunos ejemplos, están la elaboración de abonos orgánicos y bio-insecticidas, capacitación para la producción agrícola-ganadera (café, hortalizas, ganado vacuno), identificación y priorización de alternativas y diseño de proyectos sociales y productivos, economía campesina y agroindustrias, educación ambiental, relaciones de género, prevención de enfermedades y de adicciones entre mujeres y jóvenes.

\section{Antecedentes}

Como se reporta en el estado del conocimiento sobre multiculturalismo y educación publicado por el Consejo Mexicano de Investigación Educativa (COMIE) (Bertely, Dietz \& Díaz, 2013), las investigaciones sobre DDs en la vC realizadas hasta la fecha muestran que, más que un diálogo, se lleva a cabo "una imposición académica de un tipo de saberes sobre otro" (Mateos \& Dietz, 2013, p.367). En lo que se refiere a las prácticas de vinculación comunitaria, en ocasiones se observa una tendencia por parte de los estudiantes a replicar modelos asistencialistas y paternalistas promovidos por los programas gubernamentales, lo que lleva a la realización de investigaciones de corte extractivista que, más que un diálogo, generan una "respuesta de transacción: ¿qué vas a darme a cambio?” (Alatorre, 2010, p. 339), por parte de los actores comunitarios.

7. En los cursos de primer, segundo y tercer semestre del eje de vinculación, los estudiantes aprenden técnicas como observación participante, historia de vida, entrevista, transecto, línea del tiempo, mapa comunitario, croquis, diario de campo, que aplican en cuarto semestre para realizar un diagnóstico general de la comunidad de vinculación. A partir del quinto semestre, aplican talleres participativos en las comunidades de vinculación sobre temas relacionados con la carrera de Desarrollo Sustentable. 
Estudios realizados por investigadores del Proyecto InterSaberes de la Universidad Veracruzana (Alatorre, 2009, 2010; Dietz, 2009, 2011; Dietz \& Mateos, 2010, 2011; Mendoza, 2009a y 2009b), también documentan las "confluencias entre saberessaberes decontextuales (de tipo académico) y saberes-haceres contextuales (de tipo vivencial)” (Mateos \& Dietz, 2013, p. 368), que los egresados de la UVI articulan en sus prácticas profesionales fuera de la universidad.

En su interesante tesis de maestría, Vásquez (2015) analiza este tema en el caso de la Universidad Intercultural Maya de Quintana Roo (UIMQROo), y señala que el DDS entre estudiantes y campesinos ha sido complicado porque "la comunidad universitaria se asume como los 'poseedores del saber' y la comunidad campesina como los 'necesitados del saber"' (p. 150)

Esto se ve reflejado desde la misma concepción que, en la UIMQRoo, se tiene de lo que se denomina "servicio comunitario", que se concibe como:

Una oportunidad para que la comunidad pueda beneficiarse de los conocimientos adquiridos por el estudiante durante su tránsito por la educación superior, [...] minimizar la pobreza, la intolerancia, las enfermedades, la violencia, el analfabetismo, el deterioro del medio ambiente y la pérdida de tradiciones, costumbres y por ende el deterioro cultural. (Vásquez, 2015, p. 150) ${ }^{8}$

En las conclusiones de su tesis, el autor destaca que, si bien la institucionalización de la vinculación, la sustentabilidad, la investigación acción participación y la incorporación de los sabios locales, implican un claro avance para la promoción del DDs en la VC, en el caso de la UIMQROo siguen existiendo serios obstáculos. En particular, Vásquez (2015) señala que el discurso institucional de apoyar a los sectores marginados descarta la posibilidad de desarrollar un verdadero diálogo:

Los campesinos ven a la universidad como uno más de los "agentes que hacen proyectos”, porque aun con todo el potencial de que los estudiantes son de la región, en su mayor parte hablan maya y conocen parte de la cosmovisión, tienden a considerarse como parte de los promotores de un nuevo desarrollo hacia sus comunidades $[\ldots]$ rompiendo con la posibilidad de diálogo. (p. 156)

8. Vásquez (2015) destaca la responsabilidad de los docentes de la universidad en esta visión paternalista, aun cuando éstos suelen responsabilizar a los estudiantes y a los campesinos de esta situación: Cuesta todavía en los muchachos comprender que las comunidades también tienen conocimientos válidos, $[. .$.$] y las comunidades sienten que su conocimiento es marginado, que su conocimien-$ to no es valioso como lo es en la universidad, y asumen también ese rol, y ahí entramos los maestros a buscar ese diálogo, demostrar a los estudiantes que son tan válidos los conocimientos de la luna como los conocimientos que ellos aprenden aquí en el aula para poder cultivar mejor. (p. 151) 
Otras investigaciones relevantes en relación al objeto de estudio del presente escrito son las de Ávila, Betancourt, Arias y Ávila (2016) y la de Navarro (2018), las dos relacionadas directamente con la UNICH y el tema que nos interesa.

En el escrito de Ávila et al. (2016) se analiza el tema de la vinculación comunitaria dentro del Modelo educativo de las universidades interculturales y se señala que, en el caso de la UNICH:

Se buscó fomentar la vinculación entre las comunidades y la universidad, incorporando [a] los actores comunitarios en el proceso de construcción y sistematización del conocimiento y en la búsqueda de soluciones a las problemáticas regionales, promoviendo la valoración de las lenguas y culturas de los pueblos originarios y posibilitando a los jóvenes indígenas y no indígenas formarse en el espíritu de la interculturalidad y el diálogo de saberes. (p. 764)

En el caso de la carrera de Desarrollo Sustentable de la UnICH, Ávila et al. (2016) enfatizan que la vinculación comunitaria es el eje articulador "que posibilita un diálogo intercultural y el desarrollo de alternativas junto con las comunidades" (p. 769). Se menciona que, a través de una metodología sustentada en el enfoque de la investigación-acción-participativa que los estudiantes aprenden y practican a lo largo de ocho semestres en las clases del eje de vinculación comunitaria, y que luego aplican en talleres comunitarios donde participan los habitantes de las comunidades rurales, se hace posible "el diálogo intercultural y la retroalimentación de los procesos de enseñanza-aprendizaje entre la comunidad académica formal de la universidad intercultural y la sabiduría en movimiento que pervive en las comunidades rurales indígenas" (p. 769).

Lo anterior depende del tipo de perspectiva ${ }^{9}$ de los docentes que imparten las materias del eje de vinculación comunitaria. No obstante, por lo menos en lo que concierne a la carrera de Desarrollo Sustentable, en la que, según estos autores, prevalece una perspectiva centrada en la educación popular, el eje de vinculación comunitaria se convierte en:

Una praxis comunitaria que nutre a los alumnos de un conocimiento de lo real de las comunidades rurales, que hace posible la visualización de los otros conoci-

9. Los autores mencionan cuatro perspectivas: Una positivista, por la cual las comunidades se convierten en objeto de estudio desde una perspectiva extractivista; una piadosa en la que, desde una cultura de la lástima, las comunidades son consideradas como objeto de desarrollo; una proyectistatécnica, en la que se busca resolver problemas prácticos de las comunidades; y finalmente, una perspectiva basada en la educación popular, dirigida a la formación de sujetos que incidan en la transformación de las causas estructurales de la marginación y pobreza (Ávila et al., 2016, p. 772). 


\section{Diálogo de saberes en la vinculación comunitaria}

Stefano Sartorello, Joaquín Peña Piña

mientos que perviven, que se transforman y que reivindican aspiraciones societales y procesos descolonizadores en las comunidades. (Ávila et al., 2016, p. 769) En contraste con lo reportado en el caso de la sede de San Cristóbal de Las Casas, Navarro (2018) señala que en la Unidad Oxchuc de la UNICH, ${ }^{10}$ la vinculación comunitaria "encuentra limitantes al no establecerse mecanismos de colaboración e interacción sistemática con los actores comunitarios” (p. 88).

Entre las dificultades que los estudiantes enfrentan para incidir en los procesos sociales, el autor destaca que éstos han considerado la vinculación comunitaria como "una obligación académica" (p. 98). Además, señala "la falta de seguimiento a mediano y corto plazo de los estudiantes a las comunidades con las que se vinculan" (Navarro, 2018, p. 95), así como el poco interés en participar por parte de los actores comunitarios y la prevalencia de actitudes paternalistas. Debido a lo anterior, $\mathrm{Na}$ varro argumenta que "hacen falta mecanismos que permitan fomentar una mayor participación e interacción cotidiana, creativa y dinámica entre la universidad y las comunidades" (p. 94).

Abonando a la reflexión que se desarrolla en este escrito, el autor enfatiza en la necesidad de "integrar al currículum espacios que permitan reflexionar sobre los retos y alcances que los estudiantes logran en las comunidades” (Navarro, 2018, p. 96). Para recuperar las experiencias que los propios estudiantes han madurado a lo largo de su carrera y analizar desde sus perspectivas los alcances del DDS en la vc, Navarro sugiere aprovechar el Seminario de Evaluación del Desarrollo Sustentable que los estudiantes de la carrera de Ds cursan en octavo semestre. Lo anterior es justamente lo que los autores del presente escrito hemos realizado con los 41 estudiantes de la octava y novena generación que han participado en la investigación que se reporta en este artículo.

\section{Diálogo de saberes}

Como hemos mencionado en la introducción de este escrito, el diálogo intercultural es uno de los ejes fundamentales del Modelo educativo de las universidades interculturales (Casillas \& Santini, 2006). Lo anterior queda manifiesto en la Misión de la Universidad Intercultural, en la que se señala que, a través de sus funciones sustantivas (docencia, investigación, difusión y preservación de la cultura, extensión de

10. La UNICH cuenta con una sede central en la ciudad de San Cristóbal de Las Casas y con cuatro unidades académicas en los municipios de Oxchuc, Yajalón, Las Margaritas y Salto del Agua. 
los servicios y vinculación con la comunidad), esta institución "busca favorecer un diálogo permanente de las comunidades con el desarrollo científico y cultural contemporáneo" (p. 145).

Haciendo propios los planteamientos de Fornet-Betancourt (2004), se enfatiza en que:

El enfoque intercultural se pronuncia por el desarrollo de un diálogo intercultural como estrategia para promover procesos de innovación en la construcción de nuevos conocimientos, ya que confronta elementos de diferentes horizontes y perspectivas culturales, abriendo así la posibilidad de impulsar un proceso de complementación y enriquecimiento entre la ciencia moderna y otros saberes. (p. 38 )

Es así que, en una formulación típicamente utópico-angelical (Gasché, 2008a), el diálogo intercultural en las universidades interculturales tiene el objetivo de "librar barreras de comunicación entre el conocimiento práctico y místico acumulado en la sabiduría indígena y el conocimiento científico generado en las universidades convencionales" (Casillas \& Santini, 2006, p. 34).

En un texto fundamental para comprender la perspectiva del conflicto intercultural, Jorge Gasché (2008a) desarrolla una fuerte crítica hacia las concepciones hegemónicas de la interculturalidad que, como es el caso del Modelo educativo de las universidades interculturales, adoptan la retórica del respeto mutuo de las diferencias, la tolerancia de la alteridad y la capacidad de dialogar entre culturas distintas como premisas para el desarrollo de la educación intercultural. Al respecto, Gasché considera que "tenemos aquí la utopía que sustenta el discurso educativo intercultural mayoritario (main stream) en el mundo de hoy. [...] No critico esta hipótesis por ser utópica. [...] La critico por ser una utopía 'angelical', es decir, irrealista” (Gasché, 2008a, p. 375).

En otro trabajo donde reflexiona sobre el tema central de este escrito, Gasché (2008b) complementa su tesis señalando que a todos los debates sobre diálogo de saberes "subyace entonces la relación de dominación en la que los actores de este supuesto diálogo están implicados" y, en esta línea, argumenta que "un supuesto diálogo de saberes en un sentido equilibrado, igualitario, simétrico no puede haber en un sistema social global en el cual un tipo de sociedad — capitalista, liberal, individualista, materialista, monetarizada—domina sobre otros tipos de sociedad" (pp. 15-16).

De su parte, Argueta y Pérez (2011) destacan que la academia no reconoce la validez de los saberes indígenas y, restándoles el estatus de cientificidad, niega la po- 
sibilidad de un diálogo horizontal con las disciplinas científicas. Al respecto, Shiva (2007) señala que el conocimiento occidental dominante niega al conocimiento local la condición de conocimiento sistemático, calificándolo de "primitivo" y "no científico"; de esta manera, el conocimiento local queda subsumido u oculto y se alimenta al monocultivo de la mente, haciendo desaparecer las alternativas locales.

En este sentido, es menester retomar las reflexiones de Quijano (2000) y de Walsh (2008) sobre la colonialidad del saber ${ }^{11}$ y el posicionamiento del eurocentrismo como perspectiva única de conocimiento que, particularmente en el campo educativo, "ha elevado el conocimiento y la ciencia europeos como EL marco científico-académicointelectual" (Walsh, 2008, p. 137).

Desde esta perspectiva se comprende cómo la generalización de la racionalidad occidental y su imposición como norma ontológica y lógica epistémica única, ha permitido disfrazar de universal al sistema de conocimiento occidental. Lo anterior se ha traducido en una concepción eurocéntrica y hegemónica de "lo universal” que ha permeado las instituciones educativas de todos los niveles, llegando hasta la misma universidad que, como el nombre indica, debería ser una institución plural en la que caben todos los sistemas de conocimientos de la humanidad, y no una institución que universaliza un sistema de conocimiento geo-política y epistémicamente localizado.

Las consideraciones anteriores ayudan a complejizar la reflexión sobre el tema del diálogo de saberes que se realiza en este escrito, ya que la instauración de una lógica y un modo de conocer eurocéntricos en los marcos epistemológicos, academicistas y disciplinares que orientan las instituciones educativas de nivel superior, ha determina-

11. La perspectiva decolonial se desarrolla a partir de los planteamientos de Quijano (200o) y abarca principalmente cuatro ámbitos relacionados entre sí. Como explica Walsh (2008), el primer ámbito se refiere a la colonialidad del poder, entendida como patrones de poder establecidos en la Colonia, pero que perduran hoy en día, que están basados en una jerarquía racial y en la formación y distribución de identidades sociales que borran las diferencias históricas, culturales y lingüísticas de los pueblos indígenas y afrodescendientes, convirtiéndolas en identidades comunes y negativas de indios o de negros. De esta forma, la colonialidad del poder instaló una diferencia que no es simplemente étnica y racial, sino colonial y epistémica, pasando así al campo del saber y fijando el eurocentrismo como única perspectiva de conocimiento (colonialidad del saber). El tercer ámbito es la colonialidad del ser, que se ejerce mediante la inferiorización, subalternización y deshumanización de los pueblos que no forman parte de la racionalidad formal medio-fin de la modernidad, concebida a partir del individuo "civilizado". A partir de esta racionalidad, se definen los pueblos indígenas y afrodescendientes como grupos étnicos no civilizados y, por lo tanto, necesitados de políticas especiales-compensatorias para integrarlos a la normalidad de la raza y civilización blanca o mestiza. El último eje, es el de la colonialidad de la madre tierra, que encuentra su base en la división binaria sociedad/naturaleza que descarta la integración entre seres humanos y seres de la naturaleza y entre mundos biofísicos, humanos y espirituales. 
do una fuerte desacreditación de lógicas y racionalidades otras de conocer que, lejos de representar reliquias de un pasado pre-moderno, siguen vigentes hoy en día.

Partiendo del supuesto que la racionalidad occidental es un particularismo militante disfrazado de universalismo y, por lo tanto, un poderoso instrumento de dominación cultural que relega los conocimientos indígenas al rango de "saberes locales", subordinándolos a los "conocimientos" académicos, concordamos con Walsh (2005) sobre la importancia de identificar y deconstruir aquellos "legados geopolíticos y coloniales en los que se inscribe la producción académica de conocimiento" (p. 41) para analizar, en el caso de estudio considerado, hasta qué punto y de qué forma éstos están operando para obstaculizar el diálogo con los conocimientos de los pueblos indígenas rurales.

Justamente para ello, consideramos de gran importancia retomar las aportaciones de Santos (2010), quien, a partir de la construcción de una epistemología del Sur, propone abrir el espacio para la emergencia de "formas de conocer marginadas, suprimidas y desacreditadas por la ciencia moderna" que propicien la valoración de "otros saberes y experiencias de hacer saber" (p. 45).

Luego de criticar la lógica excluyente y hegemónica a través de la cual la racionalidad eurocéntrica dominante ha descalificado los conocimientos otros y ha producido las ausencias epistémicas que caracterizan la modernidad occidental, propone una alternativa epistémica basada en una epistemología del sur. ${ }^{12}$ Las dos ideas centrales que la caracterizan son la ecología de saberes y la traducción intercultural.

El fundamento de la primera radica en el carácter incompleto de todos los sistemas de conocimiento: "no hay ignorancia o conocimiento en general; toda la ignorancia es ignorante de un cierto conocimiento, y todo el conocimiento es el triunfo de una ignorancia en particular" (de Santos, 2010, p. 59).

La segunda idea central es la traducción intercultural: "el procedimiento que permite crear inteligibilidad recíproca entre las experiencias del mundo" (de Santos, 2010, p. 62).

Santos aboga por una utopía del inter-conocimiento que permita "aprender otros conocimientos sin olvidar el propio" (p.59) y que "incide simultáneamente

12. Santos (2010) define la epistemología del sur como

el reclamo de nuevos procesos de producción y de valoración de conocimientos válidos, científicos y no científicos, y de nuevas relaciones entre diferentes tipos de conocimiento, a partir de las prácticas de las clases y grupos sociales que han sufrido de manera sistemática las injustas desigualdades y las discriminaciones causadas por el capitalismo y el colonialismo. (p. 57) 


\section{Diálogo de saberes en la vinculación comunitaria}

\section{Stefano Sartorello, Joaquín Peña Piña}

sobre los saberes y las culturas, por un lado, y sobre las prácticas y los agentes, por el otro" (p. 71).

Sus planteamientos encuentran eco en la concepción de diálogo de saberes formulada por Leff (2004):

El diálogo de saberes se inscribe en la deconstrucción del mundo globalizado atrapado en las formas de representación de la realidad que produce el logocentrismo y el pensamiento único $[. .$.$] cuestiona el proyecto totalizante del conocimiento$ objetivo y la fijación del conocimiento en el presente, de la historia basada en "hechos", de un futuro limitado a la extrapolación de las tendencias de la realidad, sin cambio, sin creatividad, sin posibilidad. (p. 18)

En la formulación de este autor, el DDs parte del reconocimiento de la necesidad de conocer, aprender y comprender de y con el otro, sin pretender 'traducir 'lo otro' en términos de lo mismo" (Leff, 2004, p. 9), asumiendo el gusto por "la tensión dialéctica del vacío de sentido, de lo que falta por decir al ponerse en tensión dos palabras, dos sentencias, dos propuestas, dos razones, dos argumentaciones" (p. 3 ).

Es un tipo de diálogo profundamente intercultural que parte del reconocimiento de los saberes locales que aportan sus experiencias y se suman al conocimiento científico, pero que cuestiona la existencia de una vía única para llegar al conocimiento. Un diálogo que "no aspira a la analogía ni a la reducción de la diversidad de sentidos en las homologías de significantes, en su sumisión a un discurso que recoja sus puntos comunes haciendo de lado sus diferencias, sus polisemias" (Leff, 2004, p. 13). Un diálogo que no disuelve en un consenso las diferencias y que "más que una fusión o reconciliación entre opuestos, produce una demasía que se da en el encuentro con los demás" (p. 20).

\section{DDS en la VC: Experiencias y comprensiones de los estudiantes de la UNICH}

Como señalamos al inicio de este escrito, el corpus que sustenta los análisis que se reportan en este apartado se integró a partir de dos talleres presenciales en los que, además de recuperar los saberes previos de los 41 estudiantes participantes, se definieron tres dimensiones analíticas interconectadas que, posteriormente, estos jóvenes utilizaron como ejes guía para reflexionar por escrito acerca del DDS en la VC, sistematizando de esta forma las experiencias vividas en las prácticas de vinculación 
comunitarias realizadas a lo largo de su carrera en diferentes comunidades de los Altos de Chiapas. ${ }^{13}$

Antes de presentar los hallazgos que emergieron del análisis de este corpus, sin embargo, nos parece importante explicar algunas características de los 41 estudiantes (19 hombres y 22 mujeres) de la licenciatura en Desarrollo Sustentable de la Universidad Intercultural de Chiapas, 23 de los cuales ( 12 hombres y 11 mujeres) pertenecen a la octava generación (2012-2016), y 18 (siete hombres y 11 mujeres), a la novena (2013-2017).

Reflejando las tendencias registradas entre la población estudiantil de la licenciatura en Desarrollo Sustentable de la UNICH, sede San Cristóbal, ambos grupos se caracterizan por un equilibrio entre hombres y mujeres. Con respecto al factor étnico, aunque no contamos con datos exactos, nuestro conocimiento de los jóvenes de

13. En el caso de la octava generación, las comunidades en las que los estudiantes realizaron sus prácticas de vinculación fueron las siguientes: la pequeña comunidad tsotsil ( 7 familias, alrededor de 50 habitantes) de Guadalupe La providencia (municipio de Teopisca), caracterizada por un grado alto de marginación socioeconómica, cuyos pobladores son de religión católica y se dedican a la agricultura de subsistencia y a la producción de carbón; el barrio de San Sebastián de la cabecera municipal de Huixtán, caracterizado por una importante pluralidad religiosa (católicos, adventistas y evangélicos), con un nivel bajo de marginación, y habitado por 90 familias mestizas y tsotsiles que se dedica principalmente a la producción y venta de artesanía, servicios de transporte y producción agrícola; la pequeña comunidad ( 20 familias) de agricultores tsotsiles de Jocolhó en San Andrés Larráinzar, también caracterizada por la presencia de diversas religiones y por niveles altos de marginación; el barrio San Francisco en el municipio de Amatenango del Valle, cuya población, integrada por siete familias (47 habitantes), es de religión católica y se dedica a la agricultura de temporal y de riego; el Ejido 15 de marzo en Ocosingo ( 30 familias, 200 habitantes), cuyos pobladores tseltales de religión católica y presbiteriana, se dedican principalmente a la agricultura de milpa y a la cafeticultura; la ranchería Buenavista, ubicada a pocos kilómetros de la ciudad de San Cristóbal de Las Casas, cuyos habitantes tsotsiles (22 familias) se dedican a la construcción, la herrería y al transporte; la comunidad tsotsil de Xulumó (5o familias), ubicada en el municipio de Aldama, cuyos pobladores, de religión católica y evangélica, además de dedicarse a la agricultura de la milpa, son productores de flores (gladiolas) para el mercado regional; la comunidad tsotsil de Betania (2,010 habitantes), fundada en los años ochenta del siglo XX por población evangélica expulsada del municipio católico tradicionalista de San Juan Chamula, y caracterizada por la presencia de siete grupos religiosos evangélicos diferentes. Ubicada sobre la carretera panamericana a pocos kilómetros de la ciudad de San Cristóbal de Las Casas, con la que sus habitantes tienen importantes relaciones comerciales, Betania cuenta con un importante mercado de productos agrícolas y se caracteriza por altos índices de migración nacional e internacional.

En el caso de la segunda generación, las comunidades de vinculación fueron: la recién mencionada comunidad tsotsil de Betania; la pequeña ranchería de San Isidro las Huertas, habitada por población mestiza que se dedica principalmente a la agricultura para la venta en los mercados de la muy cercana ciudad de San Cristóbal; el municipio tseltal de Amatenango del Valle, lugar famoso por la artesanía en barro elaborada por sus mujeres y caracterizada por una diversidad político-religiosa importante; la ya mencionada cabecera municipal de Huixtán (Datos recabados en los carteles de las exposiciones de los estudiantes realizados en los dos talleres presenciales). 
estos dos grupos con los que hemos trabajado por cuatro años, nos indica que está compuesto principalmente por jóvenes urbanos (70\%), la mayoría de los cuales (80\% aproximadamente) son de origen indígena (tsotsil y tseltal), pero que han vivido en la ciudad de San Cristóbal de Las Casas por lo menos a partir de los años en los cuales estudiaron la secundaria, mientras que $20 \%$ es de origen mestizo. El restante $30 \%$ de los dos grupos está integrado por jóvenes indígenas tsotsiles y tseltales procedentes de los municipios rurales de la región de los Altos de Chiapas, como San Juan Chamula, Zinacantán, Tenejapa, entre otros. ${ }^{14}$

Para comprender las dinámicas interétnicas que suelen caracterizar las relaciones entre estos jóvenes universitarios, remitimos a un texto publicado recientemente por uno de los coautores del presente escrito (Sartorello, 2016). ${ }^{15}$ Con respecto a la vinculación comunitaria, en este escrito se señala que:

A diferencia de lo que suele suceder en las demás asignaturas, las y los universitarios indígenas son muy cotizados a la hora de conformar los equipos de vinculación. Estos jóvenes indígenas que, a causa de sus bajas competencias académicas, no suelen ser fácilmente aceptados en los grupos de estudios por sus compañeros mestizos, son muy solicitados a la hora de integrar los equipos de vinculación, sobre todo cuando son originarios de una comunidad indígena rural y, además, son buenos hablantes de su lengua materna. [...] En las actividades de vinculación comunitaria, los universitarios indígenas que proceden del contexto rural capitalizan sus conocimientos sociales, territoriales, culturales y lingüísticos, aprovechando sus redes familiares y comunitarias para tener un acceso más fácil a las comunidades y contar con un importante apoyo local para la realización de las actividades académicas y de vinculación (diagnósticos, planeación y ejecución de proyectos productivos, socioculturales, educativos, etcétera). (pp. 746-747)

Pasemos ahora al análisis del corpus de informaciones que sustenta los hallazgos que presentamos en este artículo.

14. En el grupo de la novena generación hay dos mujeres que son originarias de localidades urbanas de otros estados de la República.

15. En este artículo se analizan las características históricas y socioculturales de San Cristóbal de Las Casas, ciudad sede de la UNICH, y se identifican el racismo y el conflicto intercultural (Gasché, 2008a) como elementos estructurales que intervienen en la configuración de relaciones conflictivas entre los diversos grupos étnicos que conforman la sociedad sancristobalense, y que se reproducen al interior de la universidad. Se muestran algunos conflictos interculturales que ocurren entre universitarios mestizos e indígenas y se destaca que la convivencia intercultural en la universidad está limitada por la presencia de fuertes asimetrías sociales, económicas y académicas. 


\section{Recuperación de saberes previos}

En ambos talleres presenciales se empezó por medio de una "lluvia de ideas" en la que, sin que se registraran diferencias significativas entre los estudiantes de las dos generaciones, se enfatizó en que este diálogo es un proceso bi-direccional, que involucra en una relación de intercambio recíproco a los estudiantes de los equipos de vinculación y los habitantes de las comunidades. Se destacó que se trata de un proceso complejo que lleva tiempo y que sólo puede darse en un "marco respetuoso", ${ }^{16}$ y en el que "entran en juego ideas, prácticas, historias, vivencias, emociones, técnicas, estrategias”.

Se mencionó que este diálogo se genera en "espacios de convivencia que van más allá de una plática”, y se caracteriza por un denso intercambio de "prácticas, historias, vivencias, emociones", "habilidades, conocimientos, experiencias".

Lo anterior refleja una concepción multidimensional del DDS que va más allá de la dimensión verbal del diálogo. En este sentido, por parte de los estudiantes se reconoció que dominar la lengua originaria que se habla en la comunidad es un factor que facilita el DDS; sin embargo, no es indispensable, ya que el DDs se realiza también en actividades prácticas (agrícolas, productivas, artesanales, alimentarias, entre otras) en las que se intercambian conocimientos, saberes, habilidades y técnicas que, aunque pueden obedecer a lógicas y racionalidades distintas y hasta contrastantes, resultan mutuamente inteligibles y detonan aprendizajes recíprocos entre estudiantes y habitantes de las comunidades.

A tal respecto, Mato (2017), refiriéndose a la oralidad como forma de transmisión del conocimiento indígena, señala que hay que tener cuidado con el uso y comprensión de esta categoría, y precisa que:

el aprendizaje de las técnicas agrícolas, de manejo ambiental, de aplicaciones terapéuticas de especies vegetales, así como de otros conocimientos de la tradición oral, no se limita a prácticas de habla (como el significante oral sugiere), sino que se realizan mediante la acción y el contexto. (p. 38 )

En este mismo sentido, Gasché (2008b) explica que los conocimientos indígenas rurales están:

socialmente compartidos entre todos los miembros de la sociedad y que están implícitos en todos los quehaceres diarios, productivos y recreativos, y en las prác-

16. Entre comillas se reportan las palabras que los propios estudiantes utilizaron para expresar sus saberes previos y que los facilitadores del taller apuntamos en hojas de papelógrafo que estaban a la vista de todos durante la exposición. 


\section{Diálogo de saberes en la vinculación comunitaria}

Stefano Sartorello, Joaquín Peña Piña

ticas ceremoniales $[. .$.$] no se trata forzosamente de conocimientos verbalizados$ que podemos aprender interrogando a la gente, sino, en gran medida, de conocimientos gestuales (saberes-haceres) [...] su existencia real es inseparable del proceso de la actividad y funcional sólo en ello, es decir, en el tipo de sociedad en la que determinada actividad se desarrolla y se puede observar. (p. 11)

Siempre con respecto a esta concepción multidimensional del DDS, es menester señalar que varios estudiantes destacaron la importancia de la dimensión interpersonal que caracteriza el DDs, relacionada con las emociones y los sentimientos, y que permite la construcción de relaciones de "amistad y confianza". Lo anterior es muy importante en la etapa de acercamiento a la comunidad, cuando los estudiantes se enfrentan a situaciones muy distintas, que oscilan entre abertura e interés o bien cierre y desinterés. Varios estudiantes coincidieron en que, en la vinculación comunitaria, "nos ponemos en juego como personas y no sólo como estudiantes universitarios". ${ }^{17}$

Reflejando cómo la vc forma parte de su proceso de formación, muchos coincidieron en que las prácticas de vinculación han permitido "propiciar un cambio de pensamiento en uno mismo, generar nuevas ideas, aprender del otro", construir "conocimientos y experiencias que generan cambios de vida”. En cuanto a esto, Gasché (2008b) observa que "el aprender conocimientos indígenas puede llevarnos a la comprensión de la sociedad indígena y de sus valores como modelo social alternativo a la sociedad nuestra" (p. 16).

Los estudiantes también reconocieron la importancia de que los docentes encargados de las materias del eje de vc les provean de estrategias y técnicas para acercarse a las comunidades y, además, se quejaron de que sus maestros no suelen acompañarlos personalmente por lo menos durante las primeras prácticas de vinculación, lo que perciben como una debilidad en su proceso de formación. Sin menoscabo de estas consideraciones, hubo un consenso generalizado en el grupo sobre el hecho de que, en las clases de vinculación, aprenden métodos y técnicas para realizar diagnósticos comunitarios, talleres participativos, así como intervenciones en campos como la agroecología (producción de compostas, abonos, antiparasitarios, bio-insecticidas), que les permiten ofrecer algo a cambio a las familias de la comunidad con la que se vinculan. Sus reflexiones hacen eco a los planteamientos de Gasché (2008b), quien señala que el interaprendizaje intercultural es un proceso que se da "en situaciones

17. Se señaló que "se tiene que agradecer cuando la gente de la comunidad te da el tiempo y el espacio". Cuidar las relaciones con las personas de la comunidad es el primer paso para poder "compartir aprendizajes" y "experiencias vividas" con los comuneros. 
concretas claramente definidas y asumidas en las que la finalidad de los conocimientos adquiridos mutuamente está explícita, es decir, los beneficios mutuos del proceso de interaprendizaje están conscientemente aceptados por ambas partes” (p. 16).

Uno de los participantes destacó que el intercambio de experiencias y conocimientos entre actores comunitarios ("con sus saberes prácticos") y estudiantes ("con saberes científicos") tiene una finalidad social explícita: "identificar necesidades básicas para llegar a un bien común”. En la misma línea argumentativa, otros comentaron que el DDs con los actores comunitarios tiene como objetivo la generación "de un nuevo tipo de conocimiento, más entendible, que permita combinar el conocimiento técnico con el tradicional, como en el caso de las eco-tecnologías”.

Varios estudiantes precisaron que ellos no van a las comunidades a "enseñar, sino a colaborar, acompañar, facilitar" y, en este sentido, destacaron la importancia de "no imponer un proyecto o una postura, sino de acompañar a la comunidad". En este proceso, es importante "re-afirmar los saberes prácticos de las comunidades que ya se han comprobado en la vida real".

Se enfatizó en que "no existen respuestas únicas" ante las necesidades detectadas en las comunidades, por lo que es fundamental "no clasificar ni jerarquizar los tipos de conocimientos”. Retomando a Marglin y Apffel-Marglin (1990), consideramos que lo anterior muestra una interesante actitud de respeto cognitivo de estos estudiantes de la UNICH, que se manifiesta en la disposición y voluntad de encontrarse con el conocimiento local en un plano de igualdad.

Esta aportación permitió detonar una reflexión — de corte epistémico- sobre la importancia de valorar y dignificar los conocimientos indígenas rurales, a partir de la cual se reconoció la necesidad de documentar, formalizar y sistematizar estos conocimientos para que entren a formar parte del conocimiento científico universal, rompiendo con la ecuación entre conocimiento científico y conocimiento occidental. En nuestra consideración, la anterior es una respuesta importante ante actitudes generalizadas de dominación cognitiva de aquella academia colonizadora que, como recordábamos al recuperar las aportaciones de Quijano (2000), Walsh (2008), Argueta y Pérez (2011), suele menospreciar las definiciones locales de una situación tachándolas de "pre-modernas", "atrasadas" e "inferiores".

$\mathrm{Al}$ respecto, no es de menor relevancia que los estudiantes señalaron que en la mentalidad de la universidad y de gran parte de los profesores, "sigue predominando una concepción asimétrica del DDS en la que las comunidades son consideras objeto del DDS y no sujeto del mismo". Esto resulta evidente en el hecho de que los habitantes 


\section{Diálogo de saberes en la vinculación comunitaria}

Stefano Sartorello, Joaquín Peña Piña

de las comunidades "nunca son invitados a la universidad para compartir sus saberes en el ámbito académico”.

\section{Dimensiones analíticas del DDs en la vC}

Ahora bien, después de recuperar los saberes previos del grupo, en la segunda fase de los talleres los facilitadores propiciamos un proceso colaborativo de análisis y sistematización de estos saberes, gracias al cual identificamos — de la mano con los estudiantes participantes - tres dimensiones interconectadas por medio de las cuales analizar los alcances del DDs en la vC:

- Dimensión axiológica, valoral, ética, que surge de vivencias profundas que van más allá de un simple diálogo que los estudiantes establecen con los actores comunitarios, en las que destaca la importancia de la convivencia, del compartir y poner en juego sentimientos, emociones y valores para favorecer la intercomprensión y el interaprendizaje.

- Dimensión epistemológica, relacionada con los procesos de construcción de nuevos conocimientos interculturales y con la dignificación de las cosmovisiones indígenas para la formación de nuevos "saberes, haceres, sentires y técnicas".

- Dimensión de la acción social finalizada, ${ }^{18}$ que se refiere a las estrategias implementadas por los estudiantes en colaboración con los habitantes de las comunidades de vinculación para lograr determinados fines sociales, solucionar problemáticas específicas, propiciar cambios de vida y generar condiciones para un buen vivir.

La articulación entre estas dimensiones (que en la parte final de este artículo representaremos con la imagen de una espiral del diálogo de saberes), está muy bien expresada por lo que señaló un estudiante de la octava generación en uno de los 41 trabajos escritos que constituyen nuestro corpus:

diálogo de saberes va más allá que una simple plática, porque ésta nos permite proponer estrategias de solución de conflictos; [...] estos diálogos de saberes son

18. Es necesario señalar que, en el caso de la novena generación, esta dimensión se había dividido en dos: una dimensión metodológica, relacionada con las estrategias y técnicas, y una dimensión de la acción finalizada, relacionada con los objetivos a lograr. La decisión de unirlas en una sola ha sido tomada por los autores del presente artículo cuando analizamos el corpus documental y consideramos que, en efecto, las reflexiones de los estudiantes ponían más énfasis en los fines que en los medios y, por lo tanto, decidimos unificarlas en una sola, como también se había hecho en el caso de la octava generación. 
bidireccionales donde aprendemos todos, donde la comunidad aprende de nosotros y nosotros hacia ellos y a través de eso se construyen o se forman nuevos conocimientos y saberes para una búsqueda del bienestar común, generando un cambio social y conciencia ambiental y de los problemas presentes en la comunidad de vinculación". (MMD) ${ }^{19}$

Como señalamos desde el inicio de este artículo, son justamente los 41 escritos elaborados por los estudiantes lo que constituye el corpus documental a través del cual, en las páginas siguientes, nos proponemos analizar los alcances y las implicaciones del DDS en la VC, sustentando nuestras interpretaciones en las experiencias y comprensiones de los propios estudiantes, complementando lo que ya observamos a partir del análisis de sus saberes previos.

\section{Dimensión axiológica, valoral, ética}

Uno de los estudiantes escribe que el DDs en la vC

se va dando de manera gradual, para poder llegar a un grado de confianza [...] el diálogo de saberes se da no solo con entablar una comunicación o hablar con otra persona, pienso yo que también se genera con los gestos, con las prácticas, con el comportamientos y actitudes de cada ser humano, y lo más importante, con los valores. (ANH)

Otra joven hace eco a estos señalamientos cuando afirma que somos agentes externos y romper esta barrera se logra creando mucha confianza hacia ellos, pues muchas veces solo somos las personas que van a sacar información de su vida [...] y esto resulta incómodo y la vinculación puede fracasar si no se sabe tratar a la gente. ( $\mathrm{YJz}$ )

En este mismo sentido, otra estudiante señala: "hemos logrado interactuar con las personas de comunidad tomándolos como sujetos y no como objetos"; y precisa que "nosotros no le enseñamos a la comunidad sino más bien ellos intercambian sus conocimientos a través de charlas, talleres, historias de vida o simplemente momentos de convivencia. Porque desde los ancianos, adultos y niños podemos aprender mucho" (SFH).

Para estos jóvenes universitarios

19. De aquí en adelante, citamos entre comillas las frases que los estudiantes de la octava y novena generación plasmaron en sus trabajos escritos. Para respetar el anonimato, se ponen acrónimos en lugar de nombres originales. 
la vinculación comunitaria, es un camino que nos promete la oportunidad de entablar pláticas que retroalimentan nuestra formación como estudiantes $[. .$.$] don-$ de la vinculación comunitaria juega un papel importante no solo para los pobladores del lugar, sino también para los estudiantes. (GBE)

Estas reflexiones, además de insistir en la importancia de las actitudes y valores que están en la base de lo que, retomando a Gasché (2008b), hemos denominado interaprendizaje intercultural, reflejan a las consideraciones de Santos (2010) sobre la incompletud de cualquier sistema de conocimiento en cuanto base epistémica de la ecología de saberes. Profundizando en esta reflexión, otro estudiante dialoga desde cerca con los planteamientos de Leff (2004) sobre la importancia de deconstruir "las formas de representación de la realidad que produce el logocentrismo y el pensamiento único" (p. 18); el estudiante destaca que

los interlocutores entran en una conversación profunda que rompe las ataduras de poder entre quien supuestamente sabe y quien no sabe, sino que la comunicación es horizontal. Cada quien entenderá al otro en sus propios términos y desde saberes distintos, pero ambos dispuestos a aprender mutuamente uno del otro. Ese deseo de mutuo aprendizaje es el sello de la paridad de sujetos de conocimiento en el diálogo de saberes. (DRP)

Por otro lado, nos parece importante señalar que algunos estudiantes argumentaron que el DDs no solo se da en las relaciones interculturales entre comuneros indígenas y estudiantes no indígenas. Al respecto, una estudiante señaló lo siguiente: "Yo soy originaria de Huixtán, pero soy de una nueva generación y ya no conocí cómo se trabaja la tierra, pero el proceso de vinculación me permitió aprenderlo” (ЕT).

Otro joven comentó que, debido a que salen de sus comunidades para estudiar desde temprana edad, los jóvenes

crecen olvidándose de las cosmovisiones, como por ejemplo en el momento de la siembra de una cierta planta como lo hacen las personas grandes [...] en qué estación de la luna se puede plantar algún cultivo [...] los jóvenes ya no saben esas técnicas ancestrales. [...] la migración y la escuela son las principales causantes de la pérdida de comunicación o la convivencia de las familias. [...] Estas actividades de vinculación favorecen a que exista una transmisión de conocimientos. (DRP)

Posiblemente nuestro interlocutor esté recuperando su propia experiencia de joven tsotsil que salió temprano de su comunidad para estudiar y que, hasta ingresar a la UNICH y ser partícipe de los procesos de vinculación comunitaria, ha podido acercarse a aquellos conocimientos que sus padres no pudieron enseñarle debido a su lejanía 
de los espacios comunitarios de generación y transmisión de conocimiento. Por un lado, lo anterior es una muestra contundente del papel aculturalizante de la escuela pública mexicana y del epistemicidio que provoca una educación escolar que históricamente no ha tomado en cuenta los sistemas de conocimientos y saberes indígenas (Bertely, 1998; Jiménez, 2011). Por otro lado, también muestra que la oportunidad de volver a encontrarse con lo que Bonfil (1988) denominó como cultura propia y que, a través de los procesos de vC, la UNICH ofrece a estos jóvenes, les permite redescubrirse como indígenas, revalorar la cultura y cosmovisión de sus ancestros. En este sentido, en su interesante tesis de maestría, en la que explora el caso de la licenciatura en Comunicación Intercultural de la Universidad Intercultural del Estado de México (UIEM), López (2017) muestra cómo "el habitus de los alumnos sufre una transformación en su paso por la universidad” (p. 101). La autora señala que, al formarse en una universidad intercultural en la que existe una tendencia a "incorporar a la dinámica de enseñanza-aprendizaje las contribuciones del conocimiento tradicional de las comunidades indígenas, y que éstos se relacionen de forma horizontal con los conocimientos científicos", los estudiantes "configuran una suerte de habitus intercultural" (p. 102) que les permite valorizar el conocimiento indígena rural. Lo anterior se vincula con la dimensión epistemológica que abordaremos a continuación.

\section{Dimensión epistemológica}

Pasemos ahora a analizar las reflexiones que los estudiantes redactaron acerca de la dimensión epistemológica del DDS en la vC que, como señalamos anteriormente, está frecuentemente relacionada con una interesante actitud de respeto cognitivo (Marglin \& Apffel-Marglin, 1990) de los estudiantes de la UNICH que promueve la dignificación de los conocimientos indígenas rurales:

El intercambio de saberes y experiencias con los habitantes del Barrio ha sido de mucha importancia para la construcción de nuestra formación, $[\ldots]$ muchas veces las epistemologías aprendidas en el aula no son de mucha utilidad en la comunidad, $[\ldots]$ los habitantes tienen probablemente más conocimiento que lo que se aprende en clase. (RRV)

Otra compañera refuerza esta idea al señalar que: “[...] es necesario tomar del aprendizaje de ellos para nutrir los procesos obtenidos en clase y porque la experiencia con la que ellos cuentan es muy valiosa, inclusive igual o más que la obtenida con un título" (RBR). 
Nos parece muy interesante ver cómo estos jóvenes universitarios están conscientes de que el DDs en la vc les ofrece la posibilidad de aprender nuevos conocimientos que obedecen a lógicas y racionalidades diferentes, lo que constituye —así lo expresan en sus palabras - una oportunidad de enriquecimiento y un importante complemento a su formación universitaria.

Evocando los planteamientos de autores como Gasché (2008c) y Boege (2008), ${ }^{20}$ uno de los alumnos menciona que en el DDs "es imprescindible tener en cuenta el complejo sistema de reciprocidad y equilibrio entre los pueblos indígenas y su medio ambiente, en el sentido de complementariedad naturaleza-cultura-territorio" (AHS). Recuperando de forma implícita la crítica de Quijano (2000) hacia la colonialidad de la madre tierra, estos jóvenes universitarios tienen muy en claro que "son conocimientos que se construyen en el lugar, están localizados o territorializados porque dependen de culturas profundamente enraizadas en los contextos simbólicos, cognitivos y naturales de su propio ambiente" (NDP).

Lo anterior nos remite nuevamente a Gasché (2008b) cuando afirma que:

Todos los conocimientos indígenas — actitudinales, gestuales, discursivos - sólo existen concretamente como componentes de actividades prácticas, observables en las comunidades, y es dentro de las actividades con motivaciones y finalidades sociales, que tenemos que situarlos siempre para comprender su sentido real. (p. 18) En las palabras de un estudiante de la UNICH, el concepto de espacio y territorio sagrado fundamentan y sustentan la esencia del pensamiento indígena, sugiriendo nuevas miradas y nuevas dinámicas de los estudios territoriales $[\ldots]$ Hay que entender el pensamiento indígena como uno solo y los saberes que circulan como el motor que propulsa las acciones que recaerán en dicho territorio. (EGG)

Haciendo eco a los planteamientos de Leff (2004), cuando sostiene que el DDs parte

20. Estos autores utilizan los términos de "territorio biocultural" y "territorio socionatural", para enfatizar la integración entre sociedades indígenas y naturaleza, y destacar que, para los pueblos indígenas, el concepto de "territorio" abarca varias dimensiones: política (que se refiere a la jurisdicción, gobierno, normas y decisiones), cultural (como espacio socialmente organizado, significativo culturalmente, en el cual se localizan, distribuyen y organizan las redes sociales de asentamiento y las acciones colectivas de un grupo), simbólica (asociada a las peregrinaciones, a los rituales y a los mitos de origen) y natural (que se refiere a los recursos naturales y a las prácticas agrícolas producidas de manera colectiva y de carácter intergeneracional y acumulativo). En particular, Boege señala: "el territorio es para los indígenas una prolongación de la expresión material de la red de relaciones que construye el conocimiento colectivo $[. .$.$] ya que el territorio y el conocimiento constituyen una$ unidad indisoluble" (p. 62). 


\section{Diálogo de saberes en la vinculación comunitaria}

Stefano Sartorello, Joaquín Peña Piña

del reconocimiento de aprender de y con el otro, sin traducirlo en términos de lo mismo, este joven subraya la importancia de

generar conceptos de desarrollo alternativos [...] encontrar un punto de partida para encausar la plenitud de los pueblos indígenas hacia un respeto más institucionalizado en donde se incluya el pensamiento indígena como una alternativa de análisis de sus propios territorios. (EGG)

Otra joven da un paso más allá en la reflexión acerca de las relaciones entre estos dos tipos de conocimientos, cuando destaca que este conocimiento tradicional o indígena, "se contrapone al racionalismo científico [...] que niega la existencia de métodos alternativos para la generación del conocimiento. [...] dialogar sobre los saberes tradicionales es también innovar recuperando el conocimiento ancestral, que para la modernidad es un ente sin valor" (LSM).

Dialogando de forma muy cercana con los planteamientos de Santos (2010) y Leff (2004), otro joven afirma que:

se trata de revalorizar los saberes locales y las capacidades que existen en ellas. [...] recuperar saberes locales, campesinos y/o indígenas en torno al manejo de los recursos naturales, pero también culturales para enfrentar las asimetrías de poder entre el capitalismo depredador y los ecosistemas indígenas. (APD)

Nos parece muy interesante observar que las últimas aportaciones que hemos reportado dan muestra de un posicionamiento epistémico crítico y decolonizador de estos jóvenes universitarios, que rompe con la asimetría entre sistemas de conocimientos que ha sido instaurada por el pensamiento moderno y por la racionalidad científica. Nuevamente consideramos que, en sus escritos, estos estudiantes están recuperando $y$ aterrizando en sus experiencias de vinculación comunitaria las aportaciones que surgen de concepciones críticas de la interculturalidad (Walsh, 2005 y 2008) y del pensamiento de-colonial (Quijano, 200o) que leyeron en clase. Como veremos en las tres siguientes aportaciones, sus reflexiones plantean una fuerte crítica político-epistémica hacia la modernidad como paradigma hegemónico del conocimiento.

El diálogo "es como una herramienta que nos conduce a la reflexión crítica sobre las visiones predominantes” (MDD), señala de manera muy acertada uno de los estudiantes. Su reflexión encuentra eco y complemento en una de sus compañeras, quien afirma de manera contundente:

Somos dependientes de la modernidad, es decir, actualmente nos han enseñado que nuestras tierras no sirven, que es más sabroso comer alimentos empaquetados y más fáciles de preparar; los programas como Oportunidades, Chiapas sin hambre, 


\section{Diálogo de saberes en la vinculación comunitaria}

Stefano Sartorello, Joaquín Peña Piña

entre otros han modificado y transformado a las personas porque influyen para que dejen de hacer sus actividades de forma tradicional; es decir, a las mujeres les dicen que la medicina occidental es la mejor, incluso las asustan para que no hagan uso de plantas medicinales, y si no acuden a consulta cada mes simplemente les quitan ese supuesto apoyo. (LSM)

Las palabras de otro joven completan de forma muy interesante este análisis:

La generación actual ha venido retomando otras ideas y conocimientos que no tienen que ver con lo que los abuelos y padres enseñan. [...] En los territorios de los pueblos originarios, sentimos más los efectos de la globalización y occidentalización debido a la imposición económica e ideológica que trunca o cambia drásticamente nuestras formas de organización social comunitaria, los conocimientos, las formas de producción y de relacionarnos con nuestro territorio, por obligarnos a abandonar o cambiar nuestra cosmovisión, por explotar nuestros recursos naturales de manera irracional, por plagiar nuestros conocimientos. (AGH)

\section{Dimensión de la acción social finalizada}

Veamos ahora cómo estas reflexiones de corte epistémico nos permiten comprender lo que algunos de los estudiantes redactaron al reflexionar acerca de la tercera dimensión analítica:

El diálogo de saberes se articula con los problemas de la comunidad [...] como por ejemplo la contaminación del suelo y del agua, dependencia gubernamental, migración y uso de agroquímicos [...] Junto con los campesinos de la comunidad se estuvieron elaborando bio-fertilizantes orgánicos, se realizaron talleres de concientización sobre las consecuencias de los agroquímicos a la salud, se diseñaron huertos orgánicos familiares para ayudar a la alimentación. (RRV)

En este sentido, una joven señala la importancia de innovar con la gente metodologías sustentables y permanentes que puedan erradicar la pobreza no a base de apoyos gubernamentales que solo envenenan a la gente mandándoles productos industriales con una serie de aditivos que afectan al ser humano, sino de una verdadera dieta alimentaria basada en la producción y la seguridad alimentaria de las diferentes familias. (Јтв)

Otro joven escribe:

Por medio del diálogo de saberes se puede llegar a obtener soluciones de ciertos problemas y necesidades de la comunidad. [...] articule de una manera integral los 


\section{Diálogo de saberes en la vinculación comunitaria}

Stefano Sartorello, Joaquín Peña Piña

diferentes saberes que se originan en la universidad e intercambiar los saberes locales que la comunidad posee, con el objetivo de crear un beneficio social a través del mejoramiento de las comunidades en los ámbitos socioculturales, ambientales y económicos. (APD)

En nuestra consideración, estas reflexiones muestran algo más que una perspectiva "proyectista-técnica" (Ávila et al., 2016, p. 772) de la vinculación comunitaria, en la que únicamente se busca resolver problemas prácticos de las comunidades; al destacar la importancia de articular los saberes universitarios con los comunitarios, este joven hace implícitamente referencia a los procesos de traducción intercultural que, en la formulación de Santos (2010), crean "inteligibilidad recíproca entre las experiencias del mundo" (p. 62) y promueven una utopía del inter-conocimiento que permite "aprender otros conocimientos sin olvidar el propio" (p. 59).

Ampliando la reflexión iniciada por sus compañeros, otra joven retoma los planteamientos de la educación popular (Freire, 1968) para señalar que "un aspecto relevante para la construcción de las condiciones para el diálogo intercultural, quizá no sea tanto predefinir el punto de llegada [...] sino garantizar la capacidad de autonomía y decisión, entre los poseedores de los saberes tradicionales" (NAP). Lo anterior, remarcan otras jóvenes, "con el fin de que en el futuro el mismo grupo comunitario sea capaz de llevar la batuta para resolver sus propios problemas internos" (ABG), y que "con el paso del tiempo la gente de la comunidad pueda aprender a ser autogestiva a través de las prácticas y talleres que se han realizado durante el proceso de vinculación comunitaria” (CGM). Concluye otra estudiante

La comunidad debe llegar a ser participativa de manera que sean ellos mismo quienes gestionen, con base en sus necesidades, diferentes proyectos o herramientas de apoyo. [...] Una ventaja de una buena vinculación, es el empoderamiento de la comunidad $[. .$.$] ya que lleva un largo proceso mediante el cual los individuos$ toman mayor control sobre sus vidas y su entorno. (YJz)

Las aportaciones anteriores dan muestra del arraigo entre estos estudiantes de una perspectiva de la vinculación comunitaria basada en la educación popular "dirigida a la formación de sujetos que incidan en la transformación de las causas estructurales de la marginación y pobreza” (Ávila et al., 2016, p. 772). 


\section{Aportes para fortalecer el diálogo de saberes en la vinculación comunitaria}

En este escrito hemos abordado el tema del diálogo de saberes en los procesos de vinculación comunitaria a partir de las experiencias y comprensiones de 41 estudiantes de la carrera de Desarrollo Sustentable de la UNICH, que participaron en un proceso metacognitivo enfocado en el análisis de alcances e implicaciones de un tema de gran relevancia en el campo de la educación intercultural.

Las tres dimensiones analíticas - axiológica, epistemológica y de la acción finalizada - que hemos identificado con base en los saberes previos que los estudiantes compartieron en los dos talleres presenciales realizados a lo largo del proyecto, así como las reflexiones que, basándose en ellas, estos 41 jóvenes universitarios plasmaron en los trabajos escritos citados en las páginas anteriores, ofrecen ideas interesantes para retroalimentar el Modelo Educativo de las Universidades interculturales (Casillas \& Santini, 2006) y enriquecer el eje de vinculación comunitaria del plan de estudios de la carrera de DS de la UNICH.

Como señalamos en la introducción, y como analizamos en la parte de los referentes teóricos, el Modelo educativo de las universidades interculturales diseñado desde las oficinas de la CGEIB (Casillas \& Santini, 2006), plantea una concepción romántica y utópica del diálogo de saberes que las experiencias y comprensiones de los estudiantes de la UNICH cuestionan, mostrando toda la complejidad de este proceso multidimensional. Es así que, más allá de dominar la lengua originaria de la comunidad para dialogar con sus habitantes, los escritos de los estudiantes que participaron en este proyecto muestran la importancia de una dimensión interpersonal del diálogo de saberes, en la que se pone énfasis en los valores, emociones y sentimientos, y en la construcción de relaciones de amistad y confianza entre estudiantes universitarios y habitantes de las comunidades. En la vinculación comunitaria "nos ponemos en juego como personas y no sólo como estudiantes", destacaron en más de una ocasión nuestros jóvenes interlocutores, manifestando toda la importancia de la dimensión axiológica como premisa fundamental de un diálogo de saberes que, retomando a Gasché (2008b), les permite abrirse a una valoración de las sociedades indígenas en cuanto "modelo social alternativo" (p. 16) a la sociedad hegemónica.

Además, los estudiantes señalaron claramente que el DDS en la vc se lleva a cabo en actividades prácticas (agrícolas, productivas, artesanales, alimentarias, entre otras) que implican otro tipo de saberes, habilidades y técnicas que no siempre se verbalizan, sino 
que se activan en la práctica. Como observamos anteriormente, aunque pueden obedecer a lógicas y racionalidades distintas y hasta contrastantes, estos saberes experienciales que se derivan de actividades concretas, son mutuamente inteligibles y detonan aprendizajes recíprocos entre estudiantes y habitantes de las comunidades. Estos "interaprendizajes interculturales" (Gasché, 2008b, p. 16) que se dan en situaciones concretas muestran que, en las experiencias de nuestros alumnos, el DDs permite la generación de un nuevo conocimiento intercultural que, en sus palabras, articula "el conocimiento técnico con el conocimiento tradicional, como en el caso de las eco-tecnologías”.

En este sentido, mientras que en la perspectiva normativa planteada desde la instancia oficial (CGEIB), la vinculación comunitaria tiene el objetivo de generar "soluciones" para resolver "problemáticas y necesidades específicas" (Casillas \& Santini, 2006, pp. 153-154) de las comunidades, en las experiencias y comprensiones de nuestros estudiantes el DDS en la vC aporta principalmente a su propia formación, complementando de manera importante los conocimientos académicos que aprendieron en las aulas universitarias. Como apuntan en sus escritos, reconocen que los habitantes de las comunidades "tienen probablemente más conocimiento de lo que se aprende en clase" (RRV) y que "la experiencia con la que ellos cuentan es muy valiosa, inclusive igual o más que la obtenida con un título" (RBR). Es así que estos jóvenes universitarios afirman que, en sus prácticas de vinculación, no pretenden enseñar o imponer los conocimientos académicos que aprendieron en las aulas de la UNICH, sino acompañar los procesos de las comunidades a partir de un diálogo respetuoso de los saberes prácticos que los habitantes de las comunidades han comprobado en la vida real. Lo anterior contrasta con los hallazgos reportados por Vásquez (2015) en la UIMQROO que hemos mencionado en los antecedentes. Lejos de reproducir las asimetrías entre conocimientos académicos y comunitarios, en sus escritos los estudiantes de la UNICH manifiestan una interesante actitud de respeto cognitivo (Marglin \& Apffel-Marglin, 1990), que es una premisa fundamental de una epistemología del Sur de la que emerjan "formas de conocer marginadas, suprimidas y desacreditadas por la ciencia moderna” (Santos, 2010, p. 45). De esa manera, estos jóvenes universitarios muestran un interesante camino para promover la dignificación y valoración de los conocimientos locales, rurales e indígenas que responden a lógicas epistémicas otras, distintas de la académica, y que están centradas en la integración entre sociedad y naturaleza (Boege, 2008; Gasché, 2008c). Es así que, en las experiencias y comprensiones de los estudiantes de la UNICH, en lugar de "traducir 'lo otro' en términos de lo mismo" (Leff, 2004, p. 9), el DDS en la vC abre la posibilidad de generar procesos de "traducción intercultural que crean inteligibilidad 
recíproca entre las experiencias del mundo" (Santos, 2010, p. 62), por medio de los cuales estos jóvenes se abren hacia otras concepciones del desarrollo que no obedecen a las lógicas dominantes, sino que brotan desde las cosmovisiones de las sociedades rurales e indígenas, como son, por ejemplo, las que se refieren a la filosofía del Buen Vivir (Paoli, 2003; Sartorello, Ávila \& Ávila, 2012). Lejos de seguir reproduciendo las estructuras de dominación que subordinan a las sociedades indígenas al modelo de desarrollo capitalista neoliberal, o de replicar modelos asistencialistas y paternalistas promovidos por los programas gubernamentales (Alatorre, 2010), estas concepciones alternativas de "desarrollo" tienen el potencial de empoderar a los actores comunitarios. Es de esta forma como estos estudiantes universitarios esperan contribuir a fortalecer las capacidades autogestivas de las comunidades, rompiendo con la dependencia de los programas compensatorios impulsados por el Estado y sus apéndices, y generando soluciones más integrales y holísticas a las problemáticas comunitarias.

Pareciera entonces que las reflexiones elaboradas por los estudiantes de la UNICH muestran que, como señala uno de los antecedentes mencionados en este escrito (Ávila et al., 2016), el enfoque de la investigación-acción-participativa que caracteriza el eje de vinculación comunitaria de la carrera de Desarrollo Sustentable está propiciando un acercamiento más dialógico y horizontal entre los saberes universitarios y los de las comunidades. Como se ha observado en el caso de los egresados de la UVI señalados en los antecedentes (Mateos \& Dietz, 2013), lo anterior promueve confluencias y articulaciones entre saberes de tipo académicos con otros de tipo vivencial.

No obstante, en sus escritos los estudiantes señalaron también cuestionamientos importantes que no podemos omitir. Entre ellos, destacaron la necesidad de un mayor involucramiento institucional de la UNICH en los procesos de vinculación comunitaria: "es necesario que las autoridades universitarias tengan conocimiento de la importancia y valor de establecer vínculos con las comunidades originarias", "la institución educativa debe hacer investigación científica y hacer uso de la tecnología poniéndolos al servicio de la comunidad, y desde luego siempre para beneficio y no perjudicar los conocimientos locales" (APD).

También se señaló que la UNICH "debería no solo inculcar el compromiso social con las comunidades sino llevarlo a cabo de manera colectiva con los alumnos y con la comunidad” ( јтв). Se argumentó que entre los directivos y el cuerpo docente de la UNICH sigue predominando una concepción extractivista y asimétrica de la vinculación comunitaria y del diálogo de saberes que, hasta la fecha, ha impedido que sabios y expertos de las comunidades rurales e indígenas compartan sus conocimientos en 
la propia universidad. En este sentido, a partir de los aportes de los estudiantes, nos parece necesario promover un debate crítico al interior de la UNICH con el fin de generar las condiciones para que permita abrir sus puertas a los depositarios de los conocimientos rurales e indígenas, para que ingresen en pie de igualdad a un espacio como la universidad, que históricamente se ha convertido en el símbolo de la dominación del conocimiento académico sobre el conocimiento local y comunitario.

Finalmente, nos parece relevante concluir este escrito retomando la imagen de la espiral del diálogo de saberes para representar la importancia de la interconexión entre las tres dimensiones analíticas del DDs en la vc que hemos identificado. Con esta imagen aludimos a la complejidad de un tipo de diálogo que, en nuestra consideración, no puede prescindir de estas tres dimensiones y que, justo por ello, encuentra en la articulación entre ellas su razón de ser. Lo que nos enseñan las experiencias y comprensiones de los estudiantes que participaron en este proyecto es que el diálogo de saberes encuentra su origen en una dimensión axiológica, valoral y ética que califica la relación intercultural entre universitarios y habitantes indígenas rurales de las comunidades de vinculación. Relaciones vivas, relaciones cara a cara con la otredad que propician conocimiento, intercambio y que, como señala Schmelkes (2013) pueden posibilitar el respeto y, en ocasiones, el aprecio mutuo. Como destacan estos jóvenes universitarios, estas interacciones vis a vis van más allá de una simple plática, ponen en juego sentimientos, emociones y valores, implican estar y convivir y, solo después de un largo y denso proceso, pueden permitir alcanzar lo que con Gasché (2008b) hemos denominado inter-comprensión e inter-aprendizaje intercultural. Son justamente estos dos inter los que constituyen las premisas básicas para acceder a las otras dos dimensiones (epistémica y de la acción finalizada) que hemos identificado. No obstante, lejos de ser un proceso lineal que parte de la primera dimensión para llegar a la tercera, se trata más bien de un proceso en espiral, donde son justamente los ires $y$ venires entre las tres dimensiones los que propician procesos de profundización y consolidación continuos de cada dimensión.

Los testimonios de los estudiantes de la UNICH que hemos reportado en las páginas anteriores, muestran que estos procesos dialógicos en espiral pueden posibilitar un diálogo de saberes fundamentado en actitudes de respeto cognitivo que propician un cuestionamiento personal, epistémico y político explícito por parte de estos jóvenes universitarios que, en ocasiones, les permite romper con las estructuras de dominación que suelen caracterizar las relaciones profundamente asimétricas entre conocimiento académico universitario y conocimiento indígena rural. 


\section{Lista de referencias}

Alatorre, F. (2009). El largo y sinuoso camino hacia la conformación de redes de saberes y haceres en las regiones interculturales de Veracruz. En L. Mateos (Ed.), Los estudios interculturales en Veracruz: perspectivas regionales en contextos globales (pp. 223-244). Xalapa, México: Universidad Veracruzana-Universidad Veracruzana Intercultural.

Alatorre, F. (2010). La instrumentación de un modelo educativo basado en el diálogo y la investigación vinculada con actores comunitarios: logros, tropiezos y retos de la Universidad Veracruzana Intercultural. En C. Velasco \& Z. Jablonska (Coords.), Construcción de políticas educativas interculturales en México: debates, tendencias, problemas, desafíos (pp. 317-344). México: Universidad Pedagógica Nacional.

Argueta, A., \& Pérez, M. (2011). Saberes indígenas y diálogo intercultural. En A. Argueta, E. Corona \& P. Hersh (Coords.), Saberes colectivos y diálogo de saberes en México. México: Universidad Nacional Autónoma de México-Centro Regional de Investigación Multidisciplinaria / Instituto Nacional de Antropología e Historia/Universidad Iberoamericana.

Ávila, L., Betancourt, A., Arias, G., \& Ávila, A. (2016). Vinculación comunitaria y diálogo de saberes en la educación superior intercultural en México. Revista Mexicana de Investigación Educativa, 21(70), 759-783.

Bertely, M. (1998). Educación indígena del siglo XX en México. En P. Latapí (Coord.), Un siglo de educación en México (Tomo II, pp. 74-110). México: Fondo de Cultura Económica.

Bertely, M., Dietz, G., \& Díaz, M. (Coords.). (2013). Multiculturalismo y educación 2002-2011. México: Consejo Mexicano de Investigación Educativa/Asociación Nacional de Universidades e Instituciones de Educación Superior de la República Mexicana A.C.

Boegue, E. (2008). El patrimonio biocultural de los pueblos indígenas de México. Hacia la conservación in situ de la biodiversidad y agrodiversidad en los territorios indígenas. México: Instituto Nacional de Antropología e Historia/ Comisión Nacional para el Desarrollo de los Pueblos Indígenas.

Bonfil, G. (1988). La teoría del control cultural en el estudio de los procesos étnicos. En Anuario Antropológico/86 (pp. 13-53). Brasil: Universidad de Brasilia/Tempo Brasileiro. 


\section{Diálogo de saberes en la vinculación comunitaria}

Stefano Sartorello, Joaquín Peña Piña

Casillas, L., \& Santini, L. (2006). Universidad Intercultural. Modelo Educativo. México: Secretaría de Educación Pública-Coordinación General de Educación Intercultural Bilingüe.

Dietz, G. (2009). Los actores indígenas ante la “interculturalización” de la educación superior en México: ¿empoderamiento o neoindigenismo? Revista Latinoamericana de Educación Inclusiva, 3(2), 55-75.

Dietz, G. (2011). La educación superior intercultural ante la diversidad cultural en México: una mirada etnográfica al caso veracruzano. En S. Didou \& A. Remedi (Coords.), Educación superior de carácter étnico en México: pendientes para la reflexión (pp. 187-222). México: Senado de la República/Instituto Politécnico Nacional-Centro de Investigación y Estudios Avanzados.

Dietz, G., \& Mateos, L. (2010). La etnografía reflexiva en el acompañamiento de procesos de interculturalidad educativa: un ejemplo veracruzano. Cuicuilco, $17(48), 107-131$.

Dietz, G., \& Mateos, L. (2011). Interculturalidad y educación intercultural en México: un análisis de los discursos nacionales e internacionales en su impacto en los modelos educativos mexicanos. México: Secretaría de Educación Pública-Coordinación General de Educación Intercultural Bilingüe.

Fornet-Betancourt, R. (2004). Reflexiones sobre el concepto de interculturalidad. México: Instituto de la Cooperación Internacional-Asociación Alemana para la Educación de Adultos/Centro de Cooperación Regional para la Educación de Adultos en América Latina y El Caribe/Centro de Educación de Adultos de América Latina/ Secretaría de Educación Pública-Coordinación General de Educación Intercultural.

Freire, P. (2005). Pedagogía del oprimido. México: Siglo XXI Editores.

Gasché, J. (2008a). La motivación política de la educación intercultural indígena y sus exigencias pedagógicas. ¿ Hasta dónde abarca la interculturalidad? En M. Bertely, J. Gasché \& R. Podestá (Coords.), Educando en la diversidad. Investigaciones y experiencias educativas interculturales y bilingües (pp. 367-397). Ecuador: Abya-Yala.

Gasché, J. (2008b). ¿Qué son "saberes" o "conocimientos" indígenas, y qué hay que entender por "diálogo"? Ponencia presentada en el Primer Encuentro Amazónico de Experiencias en Diálogo de Saberes de la Universidad Nacional de Colombia, Colombia. Recuperada de http://www.bdigital.unal.edu.co/2157/

Gasché, J. (2008c). Niños, maestros, comuneros y escritos antropológicos como fuentes de contenidos indígenas escolares y la actividad como punto de partida 
de los procesos pedagógicos interculturales: Un modelo sintáctico de cultura. En M. Bertely, J. Gasché \& R. Podestá (Coords.), Educando en la diversidad. Investigaciones y experiencias educativas interculturales y bilingües (pp. 279-365). Ecuador: Abya-Yala.

Jiménez, Y. (enero-abril, 2011). Los enunciados de la escuela intercultural en el ámbito de los pueblos indígenas de México. Desacatos, 35, 149-162.

Leff, E. (2004). Racionalidad ambiental y diálogo de saberes: significancia y sentido en la construcción de un mundo sustentable. Polis, Revista de la Universidad Bolivariana, 2(7).

López, G. (2017). Universidad Intercultural del Estado de México y transformación de habitus estudiantil: caso de la licenciatura en comunicación intercultural (Tesis de maestría inédita). Universidad Iberoamericana, México.

Marglin, S., \& Apffel-Marglin, F. (1990). Dominating Knowledge: Development, Culture and Resistance. Oxford: Clarendon Press.

Mateos, L., \& Dietz, G. (2013). Universidades Interculturales en México. En M. Bertely, G. Dietz \& M. Díaz (Coords.), Multiculturalismo y educación (2002-2011) (pp. 349-381). México: Consejo Mexicano de Investigación Educativa/Asociación Nacional de Universidades e Instituciones de Educación Superior de la República Mexicana A.C.

Mato, D. (2017). (Coord.). Educación Superior y Pueblos Indígenas en América Latina. Experiencias, interpelaciones y desafíos. México: Universidad Nacional Autónoma de México/Universidad Nacional Tres de Febrero.

Mendoza, G. (2009a). Construcción de políticas públicas para la interculturalización de la educación superior en México: propuestas de los estudiantes, profesores y comunidades en Veracruz. Trabajo presentado en el Tercer Encuentro Regional sobre Educación Superior Intercultural de América Latina y El Caribe del Centro de Cooperación Regional para la Educación de Adultos en América Latina y El Caribe, México.

Mendoza, G. (2009b). Building Hybrid Knowledge at the Intercultural University of Veracruz, Mexico: an anthropological study of indigenous contexts. Intercultural Education, 20(3), 211-218.

Navarro, S. (enero-julio, 2018). Perspectivas y alcances de la vinculación comunitaria. El caso de la Universidad Intercultural de Chiapas, Unidad Oxchuc. LiminaR. Estudios Sociales y Humanísticos, 16(1), 88-102.

Paoli, A. (2003). Educación, autonomía y lekil kuxlejal: aproximaciones sociolingüísticas 
a la sabiduría de los tzeltales. México: Universidad Autónoma MetropolitanaUnidad Xochimilco.

Peña, J. (julio-diciembre, 2017). La formación de profesionales en desarrollo sustentable en un programa de educación superior intercultural. CPU-e, Revista de Investigación Educativa. 25, 265-282. Recuperado de http://cpue.uv.mx/index. php/cpue/article/view/2535

Quijano, A. (2000). Colonialidad del poder y clasificación social. Journal of World Systems Research, 6(2), 342-386.

Santos, B. (2010). Refundación del Estado en América Latina. Perspectivas desde una epistemología del Sur. Ecuador: Abya-Yala.

Sartorello, S. (2014). La co-teorización intercultural de un modelo curricular en Chiapas, México. Ecuador: Abya-Yala.

Sartorello, S. (2016). Convivencia y conflicto intercultural. Jóvenes universitarios indígenas y mestizos en la Universidad Intercultural de Chiapas. Revista Mexicana de Investigación Educativa, 21(70), 719-757.

Sartorello, S., Ávila, A., \& Ávila, L. (Coords.). (2012). El buen Vivir: miradas desde adentro de Chiapas. México: Universidad Intercultural de Chiapas-Instituto Internacional de la Unesco para la Educación Superior en América Latina y El Caribe

Schmelkes, S. (enero-junio, 2013). Educación para un México intercultural. Revista Electrónica Sinéctica. 40, 1-12. Recuperado de https://sinectica.iteso.mx/index.php/sinectica/article/view/48

Shiva, V. (2007). Los monocultivos de la mente. México: Fineo/Universidad Autónoma de Nuevo León.

Vásquez, G. (2015). Estrategia de vinculación comunitaria para la sustentabilidad: un estudio de caso en la Universidad Intercultural Maya de Quintana Roo (Tesis de maestría inédita). Universidad Iberoamericana, México.

Walsh, C. (enero-junio, 2005). Interculturalidad. Conocimientos y Decolonialidad. Signo y Pensamiento, 24(46), 39-50. Recuperado de http://revistas.javeriana. edu.co/index.php/signoypensamiento/article/view/4663

Walsh, C. (julio-diciembre, 2008). Interculturalidad, plurinacionalidad y decolonialidad: las insurgencias político-epistémicas de refundar el Estado. Tabula Rasa, 9, 131-152. Recuperado de https://www.revistatabularasa.org/numeroog/ interculturalidad-plurinacionalidad-y-decolonialidad-las-insurgencias-politico-epistemicas-de-refundar-el-estado/ 